\title{
Cinsel sağlık eğitiminin hemșirelik öğrencilerinin cinsel mitlerine etkisi
}

\section{The effect of sexual health education on the sexual myths of nursing students}

\author{
Bahtıșen Kartalఠ
}

\section{öz}

AMAÇ: Bu çalışma cinsel sağlık eğitiminin hemşirelik öğrencilerinin cinsel mitlerine etkisini belirlemek amacıyla yapılmışıır.

YöNTEM: Çalışma tek gruplu ön test son test karşılaştırmalı yarı deneysel bir çalışmadır. Çalışmanın örneklemini 40 öğrenci oluşturmuştur. Bu araştırmanın verileri Tanıtıcı Özellikler Bilgi Formu ve Cinsel Mitler Ölçeği kullanılarak toplanmıştır. Verilerin değerlendirilmesinde tanımlayıcı istatistikler (yüzdelik, ortalama, standart sapma) ve bağım$l_{1}$ gruplar $t$ testi (Paired-Samples T) kullanılmıştır. Çalışmada ölçeğin Cronbach's Alfa değeri 0,91 bulunmuştur.

BULGULAR: Öğrencilerin \%62,5'inin kadın, yaş ortalamasının $22,45 \pm 0,87$ olduğu, $\% 65,0$ 'inin ilde daha uzun süreli yaşadığı, $\% 80,0$ 'inin çekirdek aileye sahip, $\% 77,5^{\prime}$ inin gelirinin giderine denk olduğu belirlenmiştir. Öğrencilerin ölçek ön test puan ortalamalarının $66,70 \pm 14,26$, son test puan ortalamalarının $55,97 \pm 15,59$ olduğu belirlenmiştir. Öğrencilerin son test puanları ön test puanlarına göre her iki cinsiyette, geniş ve çekirdek aileye sahip olanlarda, geliri giderine denk olanlarda, annesinin eğitimi okur-yazar olmayan ve ilkokul mezunu olanlarda daha düşük bulunmuştur $(\mathrm{p}<0,05)$.

SONUÇ: Cinsel sağlık eğitiminin hemşirelik öğrencilerinin cinsel mit ölçek puanlarını düşürdüğü belirlenmiştir.

Anahtar kelimeler: cinsel mit, hemşirelik öğrencileri, cinsel sağlık

\section{Gíriș}

Cinsellik bireyin sağlık, yaşam kalitesi ve genel iyilik halinin ayrılmaz bir öğesidir. ${ }^{[1]}$ Doğum öncesi dönemden itibaren başlayan cinsellik; ömür boyu devam eden, değerlerin, inançların, duyguların, kişiliklerin, tutumların, davranışların, fiziksel görünümlerin ve içinde yaşanılan toplumun şekillendirdiği bir kavramdır. ${ }^{[2]}$ Cinsel sağlık ise

Tokat Gaziosmanpaşa Üniversitesi, Sağlık Bilimleri Fakültesi, Hemşirelik Bölümü, 60100, Tokat, Türkiye

\section{Yazısma Adresi/ Correspondence:}

Dr. Öğr. Üyesi Bahtışen Kartal

Tokat Gaziosmanpaşa Üniversitesi, Sağlık Bilimleri Fakültesi, Hemşirelik Bölümü,

Tokat, Türkiye

Tel: $\quad$ +903562500011

E-mail: bahtisen.kartal@gop.edu.tr

Geliş/ Received: $\quad 14.04 .2020$

Kabul/ Accepted: 21.05 .2020

\section{ABSTRACT}

OBJECTIVE: This study was conducted to determine the effect of sexual health education on nursing students' sexual myths.

METHOD: The study is a single-group pretest-posttest comparative semiexperimental study. The sample of the study consisted of 40 students. The data of this study were collected using the Introductory Characteristics Information Form and the Sexual Myths Scale. In the evaluation of the data; descriptive statistics (percentile, mean, standard deviation), and Paired-Samples T test were used. In the study, Cronbach's Alpha value of the scale was found to be 0.91 .

RESULTS: It was determined that $62.5 \%$ of the students were women, the average age was $22.45 \pm 0.87,65.0 \%$ lived in the province most of their lives, $80.0 \%$ had a nuclear family, $77.5 \%$ had equivalent income and expenditure. It was determined that the mean score of the pretest was $66.70 \pm 14.26$, and the mean score of the posttest was $55.97 \pm 15.59$. It was determined that posttest scores of students of both sexes, those with large and nuclear families, those whose income was equal to their expenditures, and those whose mothers were illiterate and primary school graduates were lower than their pretest scores $(\mathrm{p}<0.05)$.

CONCLUSION: It was determined that sexual health education decreased nursing students' sexual myth scale scores.

Keywords: sexual myth, nursing students, sexual health

Dünya Sağlık Örgütü tarafından; "cinsellik ile ilgili olarak fiziksel, mental ve sosyal yönden iyi olma hali” olarak tanımlanmaktadır. ${ }^{[3]}$ Cinsel sağlık insan yaşamında önemli bir yere sahiptir ve cinsel sağlık ilişkileri, mutluluğu ve yaşam kalitesini etkilemektedir. ${ }^{[4]}$

Bireylerin çeşitli sebeplerle cinsel sağlıkları bozulabilir ve sağlık profesyonelleri bu sorunların çözümünde yardım alınacak birincil grupta yer alır. Sağlık profesyonelleri içerisinde hemşirelerin bakım verdikleri bireylerin bütüncül bakımını sağlayabilmek için onların cinsel sağlık sorunlarını değerlendirme ve sorunların çözümünde danışmanlık yapma sorumlulukları vardır. Yapılan çalışmalar, sağılı uzmanlarının bakım altındaki bireylerin cinsellikle ilgili rehberlik ve danışmanlık gereksinimlerini ihmal ettiğini göstermektedir. Hemşirelik ve ebelik öğrencileri ile yapılan bir çalışmada, öğrencilerin \% 89,4’ünün cinsel sağlığı değerlendirmeyi 
mesleğinin bir gereği olarak gördügüu, fakat \% 57,1'inin bakım verdikleri kişilerin cinsel sağlı̆̆ını değerlendirmediği ve \% 69,3'ünün cinsel konuları tartışmaktan rahatsızlık duyduğu belirlenmiştir. ${ }^{[5]}$

Cinsel sağlığın değerlendirilmesini engelleyen birçok engel bulunmaktadır, bunlardan biri de cinsel mitlerdir. ${ }^{[5]}$ Cinsel mit; cinsellikle ilgili gerçek bilimsel verilerle bağlantılı olmayan, bireylerin kulaktan dolma bilgileri birbirine aktarmasıyla yayılan, toplumun hayal gücüyle şekillenen abartılı ve yanlış inanışlar olarak tanımlanmaktadır. ${ }^{[6]}$ Cinselliğin konuşulmadığı, tabu olarak görüldüğü toplumlarda söylentiler, abartılı yorumlar ve hikâyeler bilimsel olanın yerini alarak kalıplaşmış inançlara ve cinsel mitlere dönüşmektedir. $^{[7]}$ Cinsel mitler bireylerde çeşitli sorunların görülmesine sebep olmaktadır. Cinsel mitlerin; cinsel doyumu ${ }^{[8]}$ cinsel işlevi ${ }^{[9-11]}$ etkilediği, cinsel işlev bozukluğunu ve kaygı düzeyini artırdığg ${ }^{[12]}$ çalışmalarla ortaya konmuştur. Bireylerin cinsel mit algıları sadece kendilerinin sağlı̆̆ını etkilemekle kalmaz, etkileşimde oldukları bireylerin sağlığını da olumsuz etkileyebilir. Söyle ki sağlık profesyonellerinin cinsel mitlere ilişkin inançları bakım verdikleri bireylerin cinsel sağlık sorunlarını belirlemesini, bakımı planlamasını, uygulamasını ve danışmanlık yapabilmesini olumsuz etkileyebilmektedir. Yapılan çalışmalarda sağlık personelinin ve öğrencilerin cinsel mitlere inanma durumlarının yüksek olduğu belirlenmiştir. ${ }^{[6,13]}$ Cinsel sağlık sorunlarının hemşirelik bakımında göz ardı edilmemesi bütüncül hasta bakımı için önemli bir konudur. Bütüncül sağlık bakımının önündeki engellerden biri olan cinsel mit algılarının değiştirilmesi gerekmektedir. Hemşirelik eğitimi içerisinde cinsel sağlık ve hastaya/bireye yaklaşım özel olarak ele alınması gereken bir konudur. Bu çalışma cinsel sağlık eğitiminin hemşirelik öğrencilerinin cinsel mitleri üzerine etkisini belirlemek amacıyla yapılmıştır.

\section{GEREC VE YÖNTEM}

\section{Çalıșmanın Tipi, Yeri ve Örneklemi}

$\mathrm{Bu}$ çalışma cinsel sağlık eğitiminin hemşirelik öğrencilerinin cinsel mitleri üzerine etkisini belirlemek amacıyla yapılmıştır. Çalışma Tokat Gaziosmanpaşa Üniversitesi Sağlık Bilimleri Fakültesi hemşirelik bölümünde yürütülmüştür. Çalışma tek gruplu ön test son test karşılaştırmalı yarı deneysel bir çalışmadır.

Çalışmanın örneklemini Sağlık Bilimleri Hemşireliği 4. sınıf öğrencisi olan ve cinsel sağlık eğitimi dersleri alan 40 öğrenci oluşturmuştur.

\section{Veri Toplama Araçları}

Çalışmanın verileri kişisel bilgi forumu ve Cinsel Mitler Ölçeği kullanılarak toplanmıştır.

\section{Kișisel Bilgi Forumu}

Kişisel bilgi forumu, öğrencilerin ve ebeveynlerinin tanıtıcı özelliklerini içeren altı (6) sorudan oluşmaktadır.

\section{Seksüel Mitler Ölçeği}

Cinsel mitler ölçeği Gölbası ve ark. tarafından (2016) geliştirilmiş, geçerliliği ve güvenilirliği yapılmış bir ölçektir. Her bir madde 5'li Likert tipi bir ölçek kullanılarak derecelendirilmiştir: "tamamen katılıyorum" (5 puan), "biraz katılıyorum" (4 puan), "emin değilim” (3 puan), "katılmiyorum" (2 puan), "tamamen katılmiyorum" (1 puan). "Tamamen katılıyorum" ifadesi, yanıtlayıcının efsaneye inandığını belirtirken, "tamamen katılmıyorum” ifadesi, yanıtlayıcının efsaneye inanmadığı gerçeğini ifade eder. Ölçekten alınabilecek en düşük ve en yüksek puanlar s1rasıyla 28 ve 140 dır. Puan ne kadar yüksek olursa, cinsel mitlere inanma olasılı̆̆ 1 o kadar yüksek olur. ${ }^{[14]} \mathrm{Bu}$ çalışmada, Cronbach Alfa değeri 0,91 olarak bulunmuştur.

\section{Cinsel Sağlık Eğitimi}

Cinsel sağlık eğitimi bir ders olarak verilmiştir. Bu ders çalışmanın yapıldığı okulda seçmeli bir derstir. Çalışmanın yapıldığ $2018-2019$ eğitim öğretim yılında 47 öğrenci bu dersi seçmiştir. Öğrencilerin 1 tanesi derse devam etmediği için, 4 öğrenci çalışmada yer almak istemediği, 2 öğrenci de son testi doldurmadığ için çalışma 40 öğrenci ile tamamlanmıştır. Dersi alan öğrenciler 4. Sınıftadır. Ders haftada 2 saat olmak üzere 14 hafta sürmüştür. Dersin ilk haftasında öğrencilerle tanışılmış ve dersin işlenişiyle ilgili görüşme yapılmış, kişisel bilgi formu ve cinsel mitler ölçeği uygulanmıştır. İçerikte verilen konular işlendikten sonra 14. Haftada hem dersin değerlendirilmesi yapılmış hem de cinsel mitler ölçeği tekrar uygulanmıştır. Öğrencilere veri toplamada kullanılan formların üzerine isim yazmamaları sadece okul numaralarını yazmaları istenmiştir. Öğrencilerin bilgilerinin gizliliği bu şekilde sağlanmaya çalışılmıştır. Son testte kullanılan cinsel mitler ölçeğine de okul numaralarını yazmaları sağlanarak daha sonra formlar birleştirilmiştir.

Çalışmanın yapılabilmesi için kurum izni ve çalışmaya katılacak tüm öğrencilerden çalışmanın amacı hakkında sözlü bilgi verilerek sözel onam alınmıştır

\section{Cinsel Sağlık Eğitimi Dersinin İçeriği}

Dersin içeriğini; cinsel kimlik gelişimi, cinsel istismar, cinsel yolla bulaşan hastalıklar, bağımlılığın cinsellik üzerine etkileri, toplumsal cinsiyet ve cinselliğe yansımaları, 
cinsellikle ilgili etik sorunlar, dünyada ve Türkiye'de cinsel sağlık sorunları, dünyada kadın cinselliği ile ilgili geleneksel uygulamalar (cinsel mutilasyon vb.), cinsel sağlık eğitimi kime, ne zaman nasıl verilmeli, hastalarla cinselliği konuşabilmek konular oluşturmuştur.

\section{Verilerin Değerlendirilmesi}

Verileri değerlendirmek için SPSS 20 paket programı kullanılmıştır. Verilerin analizinde tanımlayıcı istatistikler (yüzde, ortalama, standart sapma) kullanılmış, karşılaştırmalı analizlerde bağımlı gruplar $\mathrm{t}$ testi (Paired-Samples T) kullanılmıştır.

\section{BULGULAR}

Öğrencilerin \%62,5'inin kadın, yaş ortalamasının $22,45 \pm 0,87$ olduğu, $\% 65,0^{\prime}$ 'nın ilde daha uzun süreli yaşadığı, \%80,0'ının çekirdek aileye mensup, \%77,5'inin gelirinin giderine denk olduğu, \%60,0'ının ilkokul mezunu olduğu belirlenmiştir.

Öğrencilerin ölçek ön test toplam puan ortalamalarının $66,70 \pm 14,26$, son test toplam puan ortalamalarının $55,97 \pm 15,59$ olduğu belirlenmiştir. Ayrıca ölçeğin cinsel yönelim, yas ve cinsellik, cinsel davranış, mastürbasyon, cinsel ilişki ve cinsel memnuniyet alt boyutlarında ders öncesinde ve sonrasında anlamlı fark olduğu belirlenmiştir. Bununla birlikte toplumsal cinsiyet, cinsel şiddet alt boyutlarında ders öncesinde ve sonrasında puan ortalamalarında anlamlı fark olmadığı görülmektedir (Tablo 1).

Öğrencilerin son test puanları ön test puanlarına göre her iki cinsiyette, il ve ilçe merkezinde daha uzun süreli yaşayanlarda, geniş ve çekirdek aileye sahip olanlarda, geliri giderine denk olanlarda, annesinin eğitimi okur-yazar olmayan ve ilkokul mezunu olanlarda daha düşük bulunmuştur $(\mathrm{p}<0,05)$ (Tablo 2).

\section{TARTIȘMA}

Cinsel sağlık, kişisel sağlık ve sağlıklı yaşamın önemli ve olumlu bir parçasıdır. Cinsel sağlıkla ilgili sorunlar, genel sağlığı tehdit eder ve insanları mutsuz eder. Cinsel sağlığın bozulması sadece fiziksel sağlığın kesintiye uğraması ile sonuçlanmaz, psikososyal ve ruhsal sağlığın da bozulmasına neden olmaktadır. ${ }^{[15]}$ Cinsel sağlık eğitimi ile bireylerin, çiftlerin, ailelerin ve toplulukların, cinsel sağlığı geliştirilir ve olumsuz cinsel sağlık sonuçlarından kaçınmak için gereken bilgi, motivasyon ve davranış becerileri ile donatılır. ${ }^{[16]}$ Cinsel eğitim, yalnızca bireylerin cinsel mitlerini ortaya çıkarmakla kalmaz ayrıca, sağlık profesyonellerinin kendi düşünce ve inançlarını gözden geçirmelerini de sağlayabilir. ${ }^{[17]}$ Cinsel sağlık eğitimi
Tablo 1. Öğrencilerin ön test son test cinsel mit algı puanlarının dağılımı

\begin{tabular}{lcccc}
\hline Cinsel mitler & Ön test & Son test & $t$ & $p$ \\
\hline & Mean $\pm S D$ & Mean $\pm S D$ & & \\
\hline Toplam puan & $66,70 \pm 14,26$ & $55,97 \pm 15,59$ & 6,74 & 0,000 \\
Cinsel yönelim & $17,65 \pm 4,02$ & $14,82 \pm 4,95$ & $-4,59$ & 0,000 \\
Toplumsal cinsiyet & $10,97 \pm 4,66$ & $10,02 \pm 3,85$ & 1,82 & 0,076 \\
Yas ve cinsellik & $9,00 \pm 3,12$ & $6,35 \pm 2,43$ & 4,59 & 0,000 \\
Cinsel davranış & $5,40 \pm 2,08$ & $4,70 \pm 1,82$ & $-2,58$ & 0,014 \\
Mastürbasyon & $5,45 \pm 1,94$ & $4,30 \pm 2,17$ & $-3,74$ & 0,001 \\
Cinsel şiddet & $6,92 \pm 2,17$ & $6,37 \pm 2,14$ & $-1,62$ & 0,111 \\
Cinsel ilişki & $5,52 \pm 1,79$ & $4,72 \pm 2,02$ & 2,68 & 0,011 \\
Cinsel memnuniyet & $5,77 \pm 1,59$ & $4,67 \pm 1,97$ & 4,18 & 0,000 \\
\hline
\end{tabular}

Tablo 2. Öğrencilerin ön test son test cinsel mit algı puanlarının sosyo-demografik özelliklerine göre dağııımı

\begin{tabular}{|c|c|c|c|c|}
\hline \multirow[t]{2}{*}{$\begin{array}{l}\text { Sosyo- demografik } \\
\text { değişkenler }\end{array}$} & \multicolumn{2}{|c|}{$\begin{array}{l}\text { Cinsel mit puan } \\
\text { ortalamaları }\end{array}$} & \multirow[t]{2}{*}{$t$} & \multirow[t]{2}{*}{$p$} \\
\hline & Ön test & Son test & & \\
\hline \multicolumn{5}{|l|}{ Cinsiyet } \\
\hline Kadın & $60,52 \pm 9,22$ & $49,88 \pm 11,59$ & 5,92 & 0,000 \\
\hline Erkek & $77,00 \pm 15,46$ & $66,13 \pm 16,43$ & 3,51 & 0,003 \\
\hline \multicolumn{5}{|l|}{$\begin{array}{l}\text { Daha uzun süre } \\
\text { yaşanan yer }\end{array}$} \\
\hline il merkezi & $65,07 \pm 15,64$ & $56,19 \pm 17,59$ & 4,106 & 0,000 \\
\hline İlçe merkezi & $68,11 \pm 13,12$ & $54,66 \pm 12,79$ & 6,011 & 0,000 \\
\hline Köy-bucak & $72,60 \pm 6,69$ & $57,20 \pm 10,10$ & 4,152 & 0,014 \\
\hline \multicolumn{5}{|l|}{ Aile tipi } \\
\hline Çekirdek & $67,56 \pm 15,13$ & $57,37 \pm 16,53$ & 5,63 & 0,000 \\
\hline Geniş & $65,50 \pm 9,83$ & $52,00 \pm 9,50$ & 2,94 & 0,032 \\
\hline Parçalanmış & $56,50 \pm 10,60$ & $45,50 \pm 13,43$ & 5,50 & 0,114 \\
\hline \multicolumn{5}{|l|}{ Gelir durumu } \\
\hline $\begin{array}{l}\text { Gelirim } \\
\text { giderimden az }\end{array}$ & $59,00 \pm 15,62$ & $46,66 \pm 20,23$ & 4,24 & 0,051 \\
\hline $\begin{array}{l}\text { Gelirim } \\
\text { giderime denk }\end{array}$ & $69,12 \pm 12,90$ & $58,64 \pm 15,03$ & 6,12 & 0,000 \\
\hline $\begin{array}{l}\text { Gelirim } \\
\text { giderimden fazla }\end{array}$ & $58,00 \pm 18,11$ & $46,83 \pm 13,40$ & 1,79 & 0,132 \\
\hline \multicolumn{5}{|l|}{$\begin{array}{l}\text { Annenin eğitim } \\
\text { durumu }\end{array}$} \\
\hline Okur -yazar değil & $79,25 \pm 12,97$ & $60,50 \pm 13,52$ & 3,35 & 0,044 \\
\hline İlkokul & $66,37 \pm 13,87$ & $55,29 \pm 15,67$ & 6,17 & 0,000 \\
\hline Ortaokul & $71,20 \pm 10,96$ & $63,60 \pm 14,53$ & 1,54 & 0,190 \\
\hline Lise & $55,40 \pm 8,38$ & $47,20 \pm 13,14$ & 1,23 & 0,280 \\
\hline Üniversite & $62,50 \pm 28,99$ & $58,00 \pm 31,11$ & 3,00 & 0,200 \\
\hline
\end{tabular}

\section{Babanın eğitim}

durumu

Okur -yazar değil $\quad 85,00 \pm 2,82 \quad 79,00 \pm 1,41 \quad 2,00 \quad 0,295$

ilkokul $\quad 69,07 \pm 12,38 \quad 61,50 \pm 12,22 \quad 3,23 \quad 0,007$

Ortaokul $\quad 63,66 \pm 13,61 \quad 53,33 \pm 18,83 \quad 3,02 \quad 0,029$

Lise $\quad 69,54 \pm 13,42 \quad 53,81 \pm 14,81 \quad 5,89 \quad 0,000$

Üniversite $\quad 54,85 \pm 14,90 \quad 44,00 \pm 12,81 \quad 1,92 \quad 0,102$ 
bireysel olarak cinsel sağlığı korurken aynı zamanda sağlık profesyonellerinin hasta bakımını da olumlu etkileyebilir. Cinsel sağlık eğitimi dersinin hemşirelik öğrencilerinin cinsel mitlerine etkisi belirlemek yapılan çalışmanın sonuçları bu bölümde tartışılmıştır. Çünkü hemşirelik öğrencilerinin cinsel mit inançları hemşirelik bakımına yansıyabilir ve bütüncül bakımı olumsuz olarak etkileyebilir.

Öğrencilerin ölçek ön test toplam puan ortalamalarının $66,70 \pm 14,26$ (ölçek en düşük puan 28 en yüksek puan 140) olduğu belirlenmiştir. Evcili ve Demirel'in aynı ölçeği kullanarak ebelik ve hemşirelik öğrencilerinde yaptığ çalışmada ölçek puan ortalamasını 76,43 $\pm 17,09$ olarak belirlemişlerdir. ${ }^{[5]}$ Karabulutlu ve Yılmazın farklı bir ölçek kullanarak hemşirelik öğrencilerinde yaptığı çalışmada öğrencilerin cinsel mitlerinin yüksek olduğu belirlenmiştir.

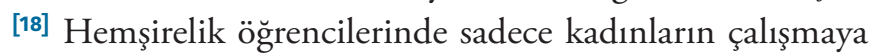
dahil edildiği başka bir çalışmada cinsel mitlerinin yüksek olduğu belirtilmiştir. ${ }^{[6]}$ Hemşirelik öğrencilerinde yapılan başka bir çalışmada da cinsel mitlerinin yüksek oluğu belirlenmiştir. ${ }^{[13]}$ Evcili ve Gölbaşı (2017)'nın aynı ölçeği kullanarak 1379 üniversite öğrencisi ile yaptığı çalışmada ölçek puanı $82,21 \pm 17,37$ olarak bulmuştur. ${ }^{[19]}$ Üniversitelerin farklı bölümlerinde öğrenim gören öğrencilerde yapılan çalışmada öğrencilerin cinsel mit algılarının yüksek olduğu tespit edilmiştir. ${ }^{[20]}$ Çalışmanın sonucu aynı ölçeğin kullanıldığı Evcili ve Demirel (2018)'in çalışmasıyla karşılaştırıldığında cinsel mit ölçek puanının daha düşük olduğu görülmektedir. Bu sonuç çalışmaların farklı bölgelerde yapılmasından kaynaklanmış olabilir.

Çalışmada cinsel sağlık eğitimi dersinin cinsel mit puanlarına etkisine bakıldığında öğrencilerin cinsel mit puanlarının son testte azaldığı belirlenmiştir. Cinsel sağlık eğitiminin cinsel mitlere etkisini ölçen literatürde sınırlı sayıda çalışmaya rastlanmıştır. Özsoy ve Bulut'un hemşirelik öğrencilerinde yaptığı bir çalışmada cinsel sağlık bilgisi dersinin cinsel mit algılarını azalttığı tespit edilmiştir. ${ }^{[21]}$ Evcili ve Gölbaşı tarafından yapılan çalışmada akran eğitimi programının cinsel mitleri azalttığı belirlenmiştir. ${ }^{[22]}$ Çalışmanın bulguları literatürle benzerdir. Cinsel sağlık eğitimi çalışmanın sınırlılıkları dâhilinde cinsel mitleri azaltmada etkilidir denebilir.

Çalışmada ön test grubundaki erkek öğrencilerin cinsel mit ölçek puanlarının daha yüksek olduğu bulunmuştur. Yapılan diğer çalışmalar da erkek öğrencilerin cinsel mitlerinin kadınlardan daha yüksek olduğu bulunmuştur. [4,18,19,23-25] Aygin ve ark. Çalışmasında kadın öğrencilerde de cinsel mitlere inanma yüksek belirlenmiştir. Aygin ve ark. sadece kadın öğrencilerde yaptı̆̆̆ bir çalışmada öğrencilerin cinsel mitlere inanma düzeyinin yüksek olduğu tespit edilmiştir. ${ }^{[26]}$ Çalışmada her iki cinsiyette de cinsel mit algılarının azaldığı belirlenmiştir. Özsoy ve Bulut'un çalışmasında cinsel sağlık bilgisi dersi alan hem kadın hem de erkek öğrencilerin ders sonrası cinsel mitlere inanma durumunun anlamlı olarak azaldığı saptanmıştır. [21] Çalışmanın bu bulgusu Özsoy ve Bulut 'un çalışmasıyla benzerdir. Her iki cinsiyette de cinsel sağlık eğitimi etkili olmuştur denebilir.

Çalışmada annesinin eğitim durumu okur-yazar olmayan ve ilkokul mezunu olanlarda, babasının eğitimi ilkokul, ortaokul ve lise olanlarda ön-test son test puanları arasında fark olduğu belirlenmiştir. Aker ve ark. çalışmasında annenin ve babanın eğitim düzeyi düştükçe cinsel mit algılarının arttığı belirlenmiştir. ${ }^{[2]}$ Evcili ve Gölbaşı'nın çalışmasında iyi eğitimli anneleri olan öğrencilerin düşük eğitimli anneleri olanlara göre daha düşük cinsel mit ortalama puanı belirlenmiştir. ${ }^{[19]}$ Ebeveynlerinin eğitim düzeyi düşük olan öğrencilerde cinsel sağlık eğitimi dersi daha etkilidir şeklinde yorumlanabilir.

\section{SONUÇ}

Öğrencilerin \%62,5'inin kadın, yaş ortalamasının $22,45 \pm 0,87$ olduğu, $\% 65,0$ 'inin ilde daha uzun süreli yaşadığı, \%80,0'inin çekirdek aileye sahip, \%77,5'inin gelirinin giderine denk olduğu belirlenmiştir. Cinsel sağlık eğitiminin hemşirelik öğrencilerinin cinsel mit ölçek son test puan ortalamalarının düştüğü belirlenmiştir. Cinsel sağlık eğitimi her iki cinsiyette, geniş ve çekirdek aileye sahip olanlarda, geliri giderine denk olanlarda, annesinin eğitimi okur-yazar olmayan ve ilkokul mezunu olanlarda, babasının eğitimi ilkokul, ortaokul ve lise olanlarda daha etkili bulunmuştur.

Sonuç olarak; Cinsel sağlık eğitimi hemşirelik öğrencilerinin cinsel mitlerini olumlu yönde etkiler denebilir. Öğrencilerin cinsel mitleri bakım verdikleri hastaların bütüncül bakımını etkilemeleri bakımından önemli olduğundan öğrencilerin mitlere inancının azaltılması için hemşirelik eğitim müfredatına bu derslerin eklenmesi önerilebilir.

\section{Hakem Değerlendirmesi \\ Dış bağımsız \\ Çıkar Çatışması \\ Yazarlar çıkar ilişkisi olmadığını beyan etmişlerdir. \\ Finansal Destek \\ Herhangi bir mali destek alınmamıştır.}

\section{Peer-review}

Externally peer-reviewed.

Conflict of Interest

No conflict of interest was declared by the authors.

Financial Disclosure

No financial support has been received. 


\section{KAYNAKLAR}

1. Kulakaç Ö. Cinsellikle ilgili bakış açıları ve çağdaş cinsellik anlayışı. Turkiye Klinikleri Obstetric-Women's Health and Diseases Nurs Special Topics 2016;2:1-8. https://www.turkiyeklinikleri. $\mathrm{com} /$ article/tr-cinsellikle-ilgili-bakis-acilari-ve-cagdas-cinsellikanlayisi-75460.html

2. Bozdemir $N$, Özcan $S$. Cinselliğe ve cinsel sağlığa genel bakış. Turk J Fam Med Primary Care, 2011;5:37-46. https://dergipark.org.tr/ tr/download/article-file/719139

3. World Health Organization (WHO). Health topics. Sexual health. https://www.who.int/topics/sexual_health/en/

4. Torun F, Torun SD, Özaydın AN. Men's belief in sexual myths and factors effecting these myths. Dusunen Adam J Psychiatr Neurol Sci 2011;24:24-31. [CrossRef]

5. Evcili F, Demirel G. Sexual myths of midwifery and nursing students and their attitude regarding the assessment of sexual health. J Hum Sci 2018;15:2280-8. [CrossRef]

6. Ejder Apay S, Balcı Akpınar R, Arslan S. Investigation of students' sexual myths. J Anatolia Nurs Health Sci 2013;16:96-102. https:// dergipark.org.tr/tr/download/article-file/29635

7. Uncu Y. Cinsel Mitler. Turkiye Klinikleri Fam Med Special Topics 2015;6:28-31.

8. Kıray Vural B, Bayık Temel A. Cinsel doyumun yormamasında bazı faktörlerin incelenmesi. Anadolu Hemşirelik Sağlık Bil Derg 2010;13:24-34. https://dergipark.org.tr/tr/download/articlefile/29506

9. Kocagöz SZ. Cinsel işlev bozukluğu tipleri ve cinsel mitler arasındaki ilişki. Uludağ Üniversitesi, Yayınlanmamış Tıpta Uzmanlık Tezi, 2008.

10. Diker G. Kadın cinsel işlev bozukluğunda cinsel mitlere inanma düzeyi, cinsel bilgi ve benlik saygısı. İstanbul: Işık Üniversitesi Sosyal Bilimler Enstitüsü, Klinik Psikoloji Yüksek Lisans Programı Yüksek Lisans Tezi; 2017. https://acikerisim.isikun. edu.tr/xmlui/bitstream/handle/11729/1276/Gizem\%20Diker. pdf?sequence $=1$ \&isAllowed $=y$

11. Erbil N. Relationship between Sexual Myths and Sexual Function of Women. Int J Caring Sci 2019;12:1570. https://pdfs.semanticscholar. org/3fe5/52bd62555d3e16b81e6008860602ad6577c9.pdf

12. Şahbaz T. Cinsel mitlerin cinsel işlev bozukluğu ve kaygı üzerine etkisi, Işıı Üniversitesi Yayınlanmamış Yüksek Lisans Tezi, 2017.
13. Ogur P, Utkualp N, Aydınoğlu N. Sağlık yüksekokulu öğrencilerinin cinsellikle ilgili inanışları. Sürekli Tıp Eğitimi Derg 2016;25:13-21.

14. Golbasi Z, Evcili F, Eroglu K, Bircan H. Sexual Myths Scale (SMS): Development, Validity And Reliability In Turkey. Sex Disabil 2016;34:75-87. [CrossRef]

15. Zeren F, Gürsoy E. Neden Cinsel Sağlık Eğitimi? Düzce Üniversitesi Sağlık Bilimleri Enstitüsü Derg 2018;8:29-33. https://dergipark. org.tr/tr/download/article-file/451039

16. Public Health Agency of Canada. Canadian Guidelines for Sexual Health Education. Her Majesty the Queen in Right of Canada; 2008. http://sieccan.org/pdf/guidelines-eng.pdf

17. Aksöyek A, Canatar T. Cinsellik ve cinsel eğitim. Turk J Fam Med Primary Care 2015;9:54-58. [CrossRef]

18. Karabulutlu Ö, Yılmaz D. Üniversite öğrencilerinde cinsiyete göre cinsel mitler. Sürekli Tip Eğitimi Derg 2018;27:155-64. https:// dergipark.org.tr/tr/download/article-file/506422

19. Evcili F, Golbasi Z. Sexual myths and sexual health knowledge levels of Turkish university students. Sex Culture 2017;21:976-90. [CrossRef]

20. Yazici S, Dolgun G, Zengin N, Onat Bayram G. The Determination of University Students' Knowledge, Attitudes and Behaviors on the Matter of Sexual Health. Sex Disabl 2012;30:67-75. [CrossRef]

21. Özsoy S, Bulut S. Cinsel sağlık bilgisi dersinin hemşirelik öğrencilerinin cinsel mitleri üzerine etkisi. Kadın Sağlığı Hemşireliği Derg 2017;3:54-67. https://dergipark.org.tr/tr/ download/article-file/386643

22. Evcili F, Golbasi Z. The effect of peer education model on sexual myths of Turkish university students: An interventional study. Perspect Psychiatr Care 2019;55:239-48. [CrossRef]

23. McMahon S. Rape myth beliefs and bystander attitudes among incoming college students. J Am Coll Health 2010;59:3-11. [CrossRef]

24. Aker S, Şahin MK, Oğuz G. Sexual Myth Beliefs and Associated Factors in University Students. Turk J Fam Med Primary Care 2019;13:472-80. [CrossRef]

25. Karasu F. Opinions of nursing students about sexual myths. Kadın Sağlığı Hemşireliği Derg 2019;5:29-42. https://dergipark.org.tr/ tr/download/article-file/926672

26. Aygin D, Açıl H, Yaman Ö, Çelik Yılmaz A. Üniversitede okuyan kadın öğrencilerin cinsel mitler ile ilgili görüşleri. Androloji Bült 2017;19:44-9. [CrossRef] 